\title{
A Numerical Model with Finite Difference Schemes for Multi-Species \\ Solute Transport in Porous Media
}

DOI:10.36909/jer.13705

\section{Amin GHAREHBAGHI}

Hasan Kalyoncu University, Faculty of engineering, Civil Engineering Department, Şahinbey, Gaziantep, Turkey, Postal Code: 27110, Email: amin.gharehbaghi@hku.edu.tr, Tel: +90 ( 342$) 2118080$

\begin{abstract}
A precise forecast of contaminant and solute transport has an inevitable role in the management of water resources. In accordance with this purpose, in this paper, a novel onedimensional numerical model for the transport of a decay chain through homogeneous porous media is proposed. To develop the suggested model, two different schemes of the finite difference method, namely the Lax-Wendroff scheme and Fourth-Order scheme, are used. The verification and validation of the established model are examined by the analytical results of three multi-species solute dispersion problems with three- and four-chain members. The total mean square error, $\mathrm{L}_{2^{-}}$and $\mathrm{L}_{\infty}$-norms are applied to assess the results. Although analyses show that both schemes provided reliable results, the numerical results of the LaxWendroff scheme are more accurate.
\end{abstract}

Keywords: Multi-species, Solute transport, Porous media, Lax Wendroff Finite Difference Method, Fourth-Order Finite Difference Method. 


\section{Introduction}

To manage surface- and ground-water resources, estimating the contaminant and solute transport phenomenon is significant. Some researchers have conducted experimental studies or developed numerical methods for groundwater problems (Kaya and Arisoy 2011; Celiker 2016; Dalkiliç and Gharehbaghi 2021). However, there are benefits in considering the phenomenon of pollutant and solute transport when examining groundwater problems. Each year by increasing the contamination of aquifers with substances such as pesticides, chlorinated solvents, and petroleum hydrocarbons the investigation of the safety of water resources becomes more significant. The transport processes of some solutes and contaminants are usually more complicated process than a first-order or pseudo first-order decay. Thus, a single-member transport model cannot predict the transformation process from the parent species to the daughter species. So far, most researchers have focused on the analytical and numerical models that could describe the phenomenon of single-member transport of various contaminants. (Kumar et al., 2010; Savovic et al., 2011; Savovic and Djordjevich 2012 \& 2013; Singh et al., 2012; Gharehbaghi 2016 \& 2017; Das et al., 2018; among many). On the other hand, most analytical solutions have limited applications. "One of the points of emphasis for analytical expressions is that application of an analytical solution is strongly affected by initial and boundary conditions. Therefore, many difficulties can encounter when dealing with complex geometries" (Gharehbaghi 2017). Three classical methods, including finite difference method (FDM), finite element method (FEM), and finite volume method (FVM), are among the most favorite numerical methods. To the best of our knowledge, the FDM is the most applied numerical technique in engineering fields. Therefore, in this study, this method is employed to develop a new numerical model. Reviews of several studies in one-dimensional (1D) form related to this paper are given here. 
Chen-Charpentier et al., (2009) suggested a numerical model for simulating the water flow, the transport of a contaminant and nutrients plus the progress of biofilm-forming microbes and biodegradation microbes in porous media for different kinetics. They announced that the governing equation was solved by using mixed-finite elements and a non-standard method. Natarajan and Kumar (2010) developed an alternative approach to the decomposition method with implicit FDM for solving multispecies transport in porous media, coupled with firstorder reactions. Ramos et al., (2011) used HYDRUS-1D software and exerted various experimental researches to predict soil sodification and salinization possibilities. They solved the equations with Galerkin-type linear FEM. Torlapati (2013) proposed a multi-component reactive transport model by using explicit forms of backward difference FDM, total variation diminishing schemes, and fully implicit approaches to predict the fate and transport of biochemical and geochemical reactive transport problems in a 1D condition. Bagalkot and Kumar (2015) introduced a 1D numerical assessment with FDM for multispecies radionuclide transport in a single-horizontal coupled fracture-matrix system. Sharma et al. (2016) investigated the impact of distance-dependent dispersion on multispecies solute transport process with upwind- and central-difference approaches of implicit FDM, as well as constant, linear, and exponential dispersivity functions. Zhang et al., (2018) proposed a 1D model for multi-component solute transport in saturated soil, according to the modified diffusion and the modified competitive Langmuir adsorption equations. To assess the results, they used the COMSOL Multiphysics software based on the FEM. Pathania et al., (2020) recommended a numerical model based on the meshless element-free Galerkin method to calculate groundwater flow and multispecies reactive transport coupled with sequential decay reactions in unconfined aquifers. They analyzed the outcomes of the recommended model by using FDM, FEM, and MODFLOW-RT3D. 
This paper presents the implementation and results of a novel numerical model to predict the multi-species solute transport phenomenon in 1D form with Advection-Dispersion Equation (ADE). The suggested model has employed two powerful schemes of FDM include the Lax Wendroff Finite Difference Method (LWFDM) and Fourth-Order Finite Difference Method (FOFDM). Finally, three analytical solutions from the researches of Bauer et al., (2001) and Pérez Guerrero et al., (2009) are applied to evaluate the performance of the proposed model.

\section{Transport model}

A sequential chemical intermediates or radionuclides coupled with first-order decay processes form a decay chain. The general pattern of sequential multi-species solute transport in porous media can describe using the following equation. (Bauer et al. 2001; Pérez Guerrero et al. 2009).

$R_{m} \frac{\partial C_{m}}{\partial t}=D \frac{\partial^{2} C_{m}}{\partial x^{2}}-v \frac{\partial C_{m}}{\partial x}-R_{m} \lambda_{m} c_{m}+R_{m-1} \lambda_{m-1} c_{m-1} ; \quad m=1, \ldots, M ; \quad \lambda_{0}=0 ; \quad 0<$

$x<\infty ; t>0$

where $c_{m}, R_{m}, D, v, \lambda_{m}, x$, and $t$ are the concentration of the $m^{\text {th }}$ member of the decay chain formed by $M$ species, the retardation coefficient for the $m^{\text {th }}$ species, the dispersion coefficient, the constant pore water velocity, the first-order decay constant for the $m^{\text {th }}$ species, the longitudinal axis, and time, respectively. The $R_{m} \lambda_{m}$ is replaced by the indicate of $k_{m}$ for simplification.

\section{Numerical solution}

As noted previously, in this paper two schemes of FDM (i.e., LWFDM and FOFDM) are employed to solve the multi-species solute transport in porous media. For the beginning, by replacing the value of $m$ as one in Eq. (1) (i.e., $m=1$ ), the required equation for the first member is given as follows: 
$R_{1} \frac{\partial C_{1}}{\partial t}=D \frac{\partial^{2} C_{1}}{\partial x^{2}}-v \frac{\partial C_{1}}{\partial x}-k_{1} C_{1} \quad 0<x<\infty, \quad t>0$

In this step, the numerical solution of LWFDM is provided for the first-member. Consider the following approximations of the derivatives for the first- and second-order.

$$
\begin{aligned}
& \frac{\partial C_{1}}{\partial x}=(1-\emptyset) \frac{C_{1 i}^{t}-C_{1 i-1}^{t}}{\Delta x}+\emptyset \frac{C_{1 i+1}^{t}-C_{1 i}^{t}}{\Delta x} \\
& \frac{\partial^{2} C_{1}}{\partial x^{2}}=\frac{C_{1 i+1}^{t}-2 C_{1 i}^{t}+C_{1 i-1}^{t}}{\Delta x^{2}} \\
& \frac{\partial C_{1}}{\partial t}=\frac{C_{1 i}^{t+1}-C_{1 i}^{t}}{\Delta t}
\end{aligned}
$$

And the solution domain of the problem is divided by a mesh of grid-lines as follows:

$x_{i}=i \Delta x \quad i=0,1,2, \ldots, N_{x}$

$t_{s}=s \Delta t \quad s=0,1,2, \ldots, N_{t}$

By employing Eqs. (3-5), the solution of first-member (i.e., Eq. (2)) for LWFDM is written as follows:

$R_{1} \frac{C_{1 i}^{t+1}-C_{1 i}^{t}}{\Delta t}=D \frac{C_{1 i+1}^{t}-2 C_{1 i}^{t}+C_{1 i-1}^{t}}{\Delta x^{2}}-v\left((1-\emptyset) \frac{C_{1 i}^{t}-C_{1 i-1}^{t}}{\Delta x}+\emptyset \frac{C_{1 i+1}^{t}-C_{1 i}^{t}}{\Delta x}\right)-k_{1} C_{1 i}^{t}$

where the value of $\varnothing$ is equal to $\emptyset=\left(1-v \frac{\Delta t}{\Delta x}\right) / 2=\frac{1}{2}-v \frac{\Delta t}{2 \Delta x}$ (Appadu, 2013). By some

manipulation, Eq. (8) can rearrange as follows:

$$
\begin{aligned}
& C_{1_{i}}^{t+1}=C_{1_{i-1}}^{t}\left(\frac{\Delta t D}{R_{1} \Delta x^{2}}+\frac{v \Delta t(1-\emptyset)}{R_{1} \Delta x}\right)+C_{1}^{t}\left(\frac{-2 \Delta t D}{R_{1} \Delta x^{2}}-\frac{v \Delta t(1-\emptyset)}{R_{1} \Delta x}+\frac{v \Delta t \emptyset}{R_{1} \Delta x}-k_{1} \frac{\Delta t}{R_{1}}+1\right)+ \\
& C_{1_{i+1}}^{t}\left(\frac{\Delta t D}{R_{1} \Delta x^{2}}-\frac{v \Delta t \emptyset}{R_{1} \Delta x}\right)
\end{aligned}
$$

To calculate the LWFDM more easily, two coefficients, which we call $m_{m}$ and $n_{m}$ coefficients, are presented in total.

$$
\begin{aligned}
& m_{m}=\frac{\Delta t D}{R_{m} \cdot \Delta x^{2}} \\
& n_{m}=\frac{\Delta t v}{R_{m} \cdot \Delta x}
\end{aligned}
$$


By replacing the $m_{1}$ and $n_{1}$ coefficients in Eq. (9), the final form of solution for the firstmember for LWFDM is given as follows:

$$
\begin{aligned}
& C_{1_{i}^{t+1}}^{t+}=C_{1_{i-1}}^{t}\left(m_{1}+n_{1}(1-\emptyset)\right)+C_{1_{i}}^{t}\left(-2 m_{1}-n_{1}(1-\emptyset)+n_{1} \emptyset-k_{1} \frac{\Delta t}{R_{1}}+1\right)+ \\
& C_{1_{i+1}^{t}}^{t}\left(m_{1}-n_{1} \emptyset\right)
\end{aligned}
$$

By applying the similar solution steps, the final form of the solution for second-, third- and fourth-species for LWFDM are extracted as follows:

$$
\begin{aligned}
& C_{2 i}^{t+1}=C_{2 i-1}^{t}\left(m_{2}+n_{2}(1-\emptyset)\right)+C_{2 i}^{t}\left(-2 m_{2}-n_{2}(1-\emptyset)+n_{2} \emptyset-k_{2} \frac{\Delta t}{R_{2}}+1\right)+C_{2 i+1}^{t}\left(m_{2}-\right. \\
& \left.n_{2} \emptyset\right)+k_{1} \frac{\Delta t}{R_{2}} C_{1}^{t} \\
& C_{3 i}^{t+1}=C_{3 i-1}^{t}\left(m_{3}+n_{3}(1-\emptyset)\right)+C_{3 i}^{t}\left(-2 m_{3}-n_{3}(1-\emptyset)+n_{3} \emptyset-k_{3} \frac{\Delta t}{R_{3}}+1\right)+C_{3 i+1}^{t}\left(m_{3}-\right. \\
& \left.n_{3} \emptyset\right)+k_{2} \frac{\Delta t}{R_{3}} C_{2 i}^{t} \\
& C_{4 i}^{t+1}=C_{4 i-1}^{t}\left(m_{4}+n_{4}(1-\emptyset)\right)+C_{4}^{t}\left(-2 m_{4}-n_{4}(1-\emptyset)+n_{4} \emptyset-\frac{\Delta t}{R_{4}} k_{4}+1\right)+C_{4}^{t}{ }_{i+1}^{t}\left(m_{4}-\right. \\
& \left.n_{4} \varnothing\right)+k_{3} \frac{\Delta t}{R_{4}} C_{3}{ }_{i}^{t}
\end{aligned}
$$

In this step to solve the Eq. (2) in EFOFDM form, for each time and space step, the derivatives of the first- and second-order are expressed as follows (Kaya and Gharehbaghi, 2014, Gharehbaghi et al., 2017):

$$
\begin{aligned}
& \frac{\partial C_{1}}{\partial t}=\frac{c_{i-2}-8 c_{i-1}+8 c_{i+1}-c_{i+2}}{12 \Delta x} \\
& \frac{\partial^{2} C_{1}}{\partial x^{2}}=\frac{-c_{i-2}+16 c_{i-1}-30 c_{i}+16 c_{i+1}-c_{i+2}}{12 \Delta x^{2}} \\
& \frac{\partial C_{1}}{\partial x}=\frac{C_{1 i}^{t+1}-C_{1 i}^{t}}{\Delta t}
\end{aligned}
$$

To initiate the discretization, the Eqs. (16-18) are replaced in Eq. (2).

$R_{1} \frac{C_{1 i}^{t+1}-C_{1 i}^{t}}{\Delta t}=D \frac{-C_{1 i-2}^{t}+16 C_{1_{i-1}}^{t}-30 C_{1 i}^{t}+16 C_{1_{i+1}}^{t}-C_{1 i+2}^{t}}{12 \Delta x^{2}}-v \frac{C_{1 i-2}^{t}-8 C_{1 i-1}^{t}+8 C_{1_{i+1}}^{t}-C_{1 i+2}^{t}}{12 \Delta x}-k_{1} C_{1}^{t}$

Eqs. (6-7) have used to generate the grid-line. With some manipulation, the last form of the solution for the first-member is acquired as follows: 


$$
\begin{aligned}
& C_{1 i}^{t+1}=C_{1-2}^{t}\left(-\frac{\Delta t D}{12 \Delta x^{2} R_{1}}-\frac{\Delta t v}{12 \Delta x R_{1}}\right)+C_{1 i-1}^{t}\left(\frac{16 \Delta t D}{12 \Delta x^{2} R_{1}}+\frac{8 \Delta t v}{12 \Delta x R_{1}}\right)+C_{1 i}^{t}\left(-\frac{30 \Delta t D}{12 \Delta x^{2} R_{1}}-\frac{\Delta t k_{1}}{R_{1}}+1\right)+ \\
& C_{1_{i+1}}^{t}\left(\frac{16 \Delta t D}{12 \Delta x^{2} R_{1}}-\frac{8 \Delta t v}{12 \Delta x R_{1}}\right)+C_{1_{i+2}}^{t}\left(-\frac{\Delta t D}{12 \Delta x^{2} R_{1}}+\frac{\Delta t v}{12 \Delta x R_{1}}\right)
\end{aligned}
$$

Similar to the solution of LWFDM, two coefficients, which we call $k a_{m}$ and $k b_{m}$ coefficients, are introduced to solve FOFDM more easily.

$$
\begin{aligned}
& k a_{m}=\frac{\Delta t D}{12 \Delta x^{2} R_{m}} \\
& k b_{m}=\frac{\Delta t v}{12 \Delta x R_{m}}
\end{aligned}
$$

and the final form of discretization with FOFDM is rearranged as follows:

$$
\begin{aligned}
& C_{1 i}^{t+1}=C_{1-2}^{t}\left(-k a_{1}-k b_{1}\right)+C_{1-1}^{t}\left(16 k a_{1}+8 k b_{1}\right)+C_{1 i}^{t}\left(-30 k a_{1}-\frac{\Delta t k_{1}}{R_{1}}+1\right)+C_{1}^{t}{ }_{i+1}^{t}\left(16 k a_{1}-\right. \\
& \left.8 k b_{1}\right)+C_{1_{i+2}}^{t}\left(-k a_{1}+k b_{1}\right)
\end{aligned}
$$

By applying the similar solution process, the ultimate form of the solution for second-, thirdand fourth-species for FOFDM are extracted as follows:

$$
\begin{aligned}
& C_{2 i}^{t+1}= \\
& C_{2 i-2}^{t}\left(-k a_{2}-k b_{2}\right)+C_{2 i-1}^{t}\left(16 k a_{2}+8 k b_{2}\right)+C_{2 i}^{t}\left(-30 k a_{2}-\frac{\Delta t k_{2}}{R_{2}}+1\right)+C_{2 i+1}^{t}\left(16 k a_{2}-\right. \\
& \left.8 k b_{2}\right)+C_{2 i+2}^{t}\left(-k a_{2}+k b_{2}\right)+\frac{\Delta t k_{1}}{R_{2}} C_{1_{i}}^{t} \\
& C_{3 i}^{t+1}= \\
& C_{3 i-2}^{t}\left(-k a_{3}-k b_{3}\right)+C_{3 i-1}^{t}\left(16 k a_{3}+8 k b_{3}\right)+C_{3 i}^{t}\left(-30 k a_{3}-\frac{\Delta t k_{3}}{R_{3}}+1\right)+C_{3 i+1}^{t}\left(16 k a_{3}-\right. \\
& \left.8 k b_{3}\right)+C_{3 i+2}^{t}\left(-k a_{3}+k b_{3}\right)+\frac{\Delta t k_{2}}{R_{3}} C_{2 i}^{t} \\
& C_{4 i}^{t+1}= \\
& C_{4 i-2}^{t}\left(-k a_{4}-k b_{4}\right)+C_{4 i-1}^{t}\left(16 k a_{4}+8 k b_{4}\right)+C_{4}^{t}\left(-30 k a_{4}-\frac{\Delta t k_{4}}{R_{4}}+1\right)+C_{4 i+1}^{t}\left(16 k a_{4}-\right. \\
& \left.8 k b_{4}\right)+C_{4 i+2}^{t}\left(-k a_{4}+k b_{4}\right)+\frac{\Delta t k_{3}}{R_{4}} C_{3 i}^{t}
\end{aligned}
$$

It is worth noting that both of the methods described here are solved in explicit form. Consequently, these methods must be able to satisfy the stability condition. In this study, the 
authors employed the Courant number for testing the stability condition. Moreover, the suggested model has no limitation on the number of multi-species. However, the analytical solutions applied here have used up to four numbers of species. Therefore, in this paper, the solutions for four species are given here.

\section{Results and discussions}

To investigate the multi-species solute transport in porous media a numerical model has been developed. The analytical results of three multi-species solute transport problems introduced by Pérez Guerrero et al., (2009) and Bauer et al., (2001) were employed to analyze the accuracy and efficiency of the presented numerical model with LWFDM and FOFDM. MATLAB was employed to generate the suggested model.

In the first two case studies, the analytical outcomes of dimensionless concentration for a three-species nitrification chain $\left(\mathrm{NH}_{4}^{+} \rightarrow \mathrm{NO}_{2}^{-} \rightarrow \mathrm{NO}_{3}^{-}\right)$are used. In the first case study, the distance and duration of the problem were selected as $220 \mathrm{~cm}$ and $200 \mathrm{~h}$, respectively, and at the second case study, the distance and duration of the problem were applied as $110 \mathrm{~cm}$ and 50h (much smaller time), respectively. To calculate the essential interval values for analytical results the linear interpolation method is employed. More details about these two case studies, for instance, decay coefficient $\left(\lambda_{m}\right)$, retardation coefficient $\left(R_{m}\right)$, initial and boundary conditions, are presented in Table (1). It is important to note that in all tables and figures below, the first two case studies are referred to as the analytical results of dimensionless concentration for the three-species nitrification chain $\left(\mathrm{NH}_{4}^{+} \rightarrow \mathrm{NO}_{2}^{-} \rightarrow \mathrm{NO}_{3}^{-}\right)$introduced by Pérez Guerrero et al., (2009) for 220cm, 200h and $110 \mathrm{~cm}, 50 \mathrm{~h}$, respectively. Furthermore, case three is the analytical result of the four-member decay chain solute transport problem derived from the Bauer et al., (2001) study. Moreover, in all of the figures and tables below related to the two first cases, the $\mathrm{x}$, c, curve_1, curve_2, curve_3, LWFDM_C1, LWFDM 
_C2, LWFDM _C3, FOFDM_C1, FOFDM_C2, and FOFDM_C3 are the abbreviations of distance $(\mathrm{cm})$, concentration $(\mathrm{mM})$, outcomes of analytical expressions introduced by Pérez Guerrero et al., (2009) for $\mathrm{NH}_{4}^{+}$, outcomes of analytical expressions introduced by Pérez Guerrero et al., (2009) for $\mathrm{NO}_{2}^{-}$, outcomes of analytical expressions introduced by Pérez Guerrero et al., (2009) for $\mathrm{NO}_{3}^{-}$, calculated dimensionless concentration with a suggested model for LWFDM for $\mathrm{NH}_{4}^{+}$, calculated dimensionless concentration with a suggested model for LWFDM for $\mathrm{NO}_{2}^{-}$, calculated dimensionless concentration with a suggested model for LWFDM for $\mathrm{NO}_{3}^{-}$, calculated dimensionless concentration with suggested model for FOFDM for $\mathrm{NH}_{4}^{+}$, calculated dimensionless concentration with suggested model for FOFDM for $\mathrm{NO}_{2}^{-}$, and calculated dimensionless concentration with suggested model for FOFDM for $\mathrm{NO}_{3}^{-}$, respectively.

Table 1. Parameter values for the nitrification chain problem

\begin{tabular}{|c|c|c|c|}
\hline Description & $\mathrm{NH}_{4}^{+}(\mathrm{m}=1)$ & $\mathrm{NO}_{2}^{-}(\mathrm{m}=2)$ & $\mathrm{NO}_{3}^{-}(\mathrm{m}=3)$ \\
\hline Retardation coefficient $\left(R_{m}\right)$ & 2 & 1 & 0 \\
\hline Decay coefficient, $\lambda_{m}$ & 0 & 0 & 0 \\
\hline First case $\rightarrow C(x, 1)$ & 0 & 0.001731801827 & 0.00006174718691 \\
\hline First case $\rightarrow C(1, t)$ & 0.9982064510 & $1.255589051 \mathrm{E}-12$ & 0.0002545665546 \\
\hline First case $\rightarrow C(N, t)$ & $1.199389159 \mathrm{E}-89$ & 0 & 0 \\
\hline Second case $\rightarrow C(x, 1)$ & 0 & 0.001731801827 & 0.00006174718691 \\
\hline Second case $\rightarrow C(1, t)$ & 0.9982064510 & $1.622019705 \mathrm{E}-50$ & $2.260630087 \mathrm{E}-48$ \\
\hline Second case $\rightarrow C(N, t)$ & $5.1438380 \mathrm{E}-177$ & coefficient & $\mathrm{D}=0.18 \mathrm{~cm}^{2} \mathrm{~h}^{-1}$ \\
\hline Pore velocity $=1 \mathrm{cmh}^{-1}$ & Dispersion & & \\
\hline
\end{tabular}

The outcomes of numerical investigations for the first two case studies are illustrated in figures (1) and (2) and tables (2-4). The above-mentioned case studies have simulated with two space and time intervals. The first case has simulated with $\left(\mathrm{N}_{\mathrm{x}}=331, \mathrm{~N}_{\mathrm{t}}=800001\right)$ and $\left(\mathrm{N}_{\mathrm{x}}=441, \mathrm{~N}_{\mathrm{t}}=200001\right)$ number of nodes in space $\left(\mathrm{N}_{\mathrm{x}}\right)$ and time $\left(\mathrm{N}_{\mathrm{t}}\right)$. Similarly, the second case has employed $\left(\mathrm{N}_{x}=221, \mathrm{~N}_{t}=250001\right)$ and $\left(\mathrm{N}_{\mathrm{x}}=441, \mathrm{~N}_{t}=600001\right)$ numbers of nodes in 
space $\left(\mathrm{N}_{\mathrm{x}}\right)$ and time $\left(\mathrm{N}_{\mathrm{t}}\right)$ to solve the problem. The numerical results of the first case at a distance and time equal to $220 \mathrm{~cm}$ and $200 \mathrm{~h}$ for all the nitrogen species have illustrated in figure (1) and the numerical results of the second case at a distance and time equal to $110 \mathrm{~cm}$ and 50h for all the nitrogen species have illustrated in figure (2). Based on the numerical outcomes demonstrated in the figures, it can easily be seen that both LWFDM and FOFDM have calculated close results. Therefore, for benchmark purposes, the total mean square error (TMSE), $\mathrm{L}_{2^{-}}$and $\mathrm{L}_{\infty}$-norms are determined by the following relations. The outcomes of the comparisons have illustrated in tables (2-4).

$$
\begin{aligned}
& \text { TMSE }=\frac{\sum\left(c_{\text {Numerical solution }}-c_{\text {analytical results }}\right)^{2}}{N} \\
& \|x\|_{2}=\sqrt{x_{1}^{2}+x_{2}^{2}+\cdots+x_{N-1}^{2}+x_{N}^{2}} \\
& \|\left. x\right|_{\infty}=\max \left[\left|x_{1}\right|,\left|x_{2}\right|, \ldots,\left|x_{N}\right|\right]
\end{aligned}
$$

The numerical solutions for the transport of a decay chain in porous media are extensively applicable. "Although only radioactive decay is a true first-order process, also chemical and biological transformations can be often described approximately in terms of first-order decay" Bauer et al., (2001). As mentioned earlier, based on the numerical results demonstrated in the tables below, it can be seen that both of the LWFDM and FOFDM schemes can illustrate good agreements with the results of analytical values. To achieve a deeper focus on the applied schemes, the comparison of numerical results one by one has presented here. About the first case study, the numerical results are given in table (2) show that the FOFDM in the first- $\left(\mathrm{NH}_{4}^{+}\right)$and second-member $\left(\mathrm{NO}_{2}^{-}\right)$determined slightly better results than LWFDM. Nevertheless, the numerical outcomes of $\mathrm{L}_{2^{-}}$and $\mathrm{L}_{\infty}$-norms in tables (3-4) demonstrated that LWFDM provided more accurate results. In the second case, generally, the LWFDM obtain more precise results than FOFDM.

Fig. 1.

Fig. 2. 
Table 2. Table of TMSE for the first and second cases

\begin{tabular}{|c|c|c|c|c|c|}
\hline Description & $\mathrm{Nx}(\Delta \mathrm{x}) ; \mathrm{Nt}(\Delta \mathrm{t})$ & $\mathrm{NH}_{4}^{+}(\mathrm{m}=1)$ & $\mathrm{NO}_{2}^{-}(\mathrm{m}=2)$ & $\mathrm{NO}_{3}^{-}(\mathrm{m}=3)$ & Execution time(s) \\
\hline First case $\rightarrow$ LWFDM & $331(0.6667) ; 800001(0.00025)$ & $2.92685 \mathrm{E}-05$ & $1.11154 \mathrm{E}-06$ & $8.06441 \mathrm{E}-05$ & $2.92685 \mathrm{E}-05$ \\
\hline First case $\rightarrow$ EFOFDM & & $2.55927 \mathrm{E}-05$ & $1.03669 \mathrm{E}-06$ & $8.21961 \mathrm{E}-05$ & 512.807369 \\
\hline First case $\rightarrow$ LWFDM & $441(0.5) ; 200001(0.001)$ & $2.9121 \mathrm{E}-05$ & $1.11681 \mathrm{E}-06$ & $8.08962 \mathrm{E}-05$ & 46.771354 \\
\hline First case $\rightarrow$ EFOFDM & & $2.65833 \mathrm{E}-05$ & $1.06039 \mathrm{E}-06$ & $8.19144 \mathrm{E}-05$ & 145.763324 \\
\hline Second case $\rightarrow$ LWFDM & $221(0.5) ; 250001(0.0002)$ & 0.000138592 & $2.46814 \mathrm{E}-06$ & $1.06738 \mathrm{E}-05$ & 38.282872 \\
\hline Second case $\rightarrow$ EFOFDM & & 0.0001587 & $2.48433 \mathrm{E}-06$ & $1.13168 \mathrm{E}-05$ & 100.173238 \\
\hline Second case $\rightarrow$ LWFDM & $441(0.25) ; 600001(0.000083333)$ & 0.000148592 & $2.52067 \mathrm{E}-06$ & $1.08812 \mathrm{E}-05$ & 226.570315 \\
\hline Second case $\rightarrow$ EFOFDM & & 0.000155325 & $2.51632 \mathrm{E}-06$ & $1.11242 \mathrm{E}-05$ & 437.070194 \\
\hline
\end{tabular}

Table 3. Table of $\mathrm{L}_{2}$-norms for the first and second cases

\begin{tabular}{|c|c|c|c|c|c|}
\hline $\mathrm{L}_{2^{-}}$ & Description & $\mathrm{Nx}(\Delta \mathrm{x}) ; \mathrm{Nt}(\Delta \mathrm{t})$ & $N H_{4}^{+}(\mathrm{m}=1)$ & $\mathrm{NO}_{2}^{-}(\mathrm{m}=2)$ & $\mathrm{NO}_{3}^{-}(\mathrm{m}=3)$ \\
\hline & Analytical results of equal interval node distribution & $331(0.6667) ; 800001(0.00025)$ & 8.031114327 & 0.74391006 & 6.615388059 \\
\hline \multirow{5}{*}{ First case } & LWFDM & & 7.95209243 & 0.760873 & 6.776044 \\
\hline & EFOFDM & & 7.960036905 & 0.76095 & 6.776169 \\
\hline & Analytical results of equal interval node distribution & \multirow[t]{3}{*}{$441(0.5) ; 200001(0.001)$} & 9.264546037 & 0.85901057 & 7.638814144 \\
\hline & LWFDM & & 9.17326893 & 0.878634 & 7.824448 \\
\hline & EFOFDM & & 9.179941339 & 0.878695 & 7.824534 \\
\hline \multirow{6}{*}{ Second case } & Analytical results of equal interval node distribution & \multirow[t]{3}{*}{$221(0.5) ; 250001(0.0002)$} & 6.104308005 & 0.449497 & 0.912087457 \\
\hline & LWFDM & & 6.135397889 & 0.470967 & 0.958306 \\
\hline & EFOFDM & & 6.146293889 & 0.47112 & 0.958493 \\
\hline & Analytical results of equal interval node distribution & \multirow[t]{3}{*}{$441(0.25) ; 600001(0.000083333)$} & 8.603468 & 0.635614 & 1.289799 \\
\hline & LWFDM & & 8.649479357 & 0.666281 & 1.355536 \\
\hline & EFOFDM & & 8.656191449 & 0.66634 & 1.355607 \\
\hline
\end{tabular}

Table 4. Table of $\mathrm{L}_{\infty}$-norms for the first and second cases

\begin{tabular}{|c|c|c|c|c|c|}
\hline $\mathrm{L}_{\infty}$ & Description & $\mathrm{Nx}(\Delta \mathrm{x}) ; \mathrm{Nt}(\Delta \mathrm{t})$ & $\mathrm{NH}_{4}^{+}(\mathrm{m}=1)$ & $\mathrm{NO}_{2}^{-}(\mathrm{m}=2)$ & $\mathrm{NO}_{3}^{-}(\mathrm{m}=3)$ \\
\hline \multirow{6}{*}{ First case } & Analytical results of equal interval node distribution & \multirow[t]{3}{*}{$331(0.6667) ; 800001(0.00025)$} & 0.991726725 & 0.077019 & 0.586836973 \\
\hline & LWFDM & & 0.991382 & 0.07902 & 0.598951 \\
\hline & EFOFDM & & 0.992145 & 0.079031 & 0.599018 \\
\hline & Analytical results of equal interval node distribution & \multirow[t]{3}{*}{$441(0.5) ; 200001(0.001)$} & 0.993346656 & 0.077057 & 0.587139464 \\
\hline & LWFDM & & 0.993083 & 0.079027 & 0.598982 \\
\hline & EFOFDM & & 0.993638 & 0.079035 & 0.599027 \\
\hline \multirow{6}{*}{ Second case } & Analytical results of equal interval node distribution & \multirow[t]{3}{*}{$221(0.5) ; 250001(0.0002)$} & 0.993347 & 0.074712 & 0.146364487 \\
\hline & LWFDM & & 0.993083 & 0.077032 & 0.15312 \\
\hline & EFOFDM & & 0.993638 & 0.076832 & 0.153216 \\
\hline & Analytical results of equal interval node distribution & \multirow[t]{3}{*}{$441(0.25) ; 600001(0.000083333)$} & 0.995777 & 0.074712 & 0.146364 \\
\hline & LWFDM & & 0.995641 & 0.076886 & 0.153235 \\
\hline & EFOFDM & & 0.995895 & 0.07684 & 0.153253 \\
\hline
\end{tabular}


In the final case study, an arbitrary decay chain containing four species in a complex porous medium at $3000 \mathrm{~m}$ and 3000 days was used. Application of these distance and time values reveals that the introduced model can solve problems in the semi-infinite domain and long duration of time. The details of the problem for the third case study are illustrated in table (5). Moreover, in all of the figures and tables below related to the third case, the $\mathrm{x}$ is the abbreviation of distance $(\mathrm{cm}), \mathrm{c}$ is the abbreviation of concentration $(\mathrm{mM}), \mathrm{C} 1, \mathrm{C} 2, \mathrm{C} 3$, and $\mathrm{C} 4$, are the abbreviations of outcomes of analytical expressions for the concentration introduced by Bauer et al., (2001) for four species, LWFDM_C1, LWFDM _C2, LWFDM _C3, and LWFDM _C4, are the abbreviations of numerical results of the concentration with the suggested model for LWFDM for four species, and FOFDM_C1, FOFDM_C2, FOFDM_C3, and FOFDM_C4 are the abbreviations of numerical results of the concentration with the suggested model for FOFDM for four species, respectively. In case three we carried out four numerical experiments to investigate the developed model more deeply, including $N_{x}=1001, N_{t}=15001 ; N_{x}=1501, N_{t}=30001 ; N_{x}=2001, N_{t}=40001 ;$ and $N_{x}=2001, N_{t}=60001$. Parallel to the two first cases, the TMSE, $\mathrm{L}_{2^{-}}$and $\mathrm{L}_{\infty}$-norms are calculated. The numerical results have presented in tables (6-8). The numerical outcomes of concentration distributions for the four-member decay chain for $\mathrm{N}_{\mathrm{x}}=1001, \mathrm{~N}_{\mathrm{t}}=15001$ in case three, are demonstrated in figure (3). The numerical results have given in table (6) show that in the third case, LWFDM calculates more reliable TMSE results than FOFDM. Numerical outcomes in table (7) clarify that except for third-member the results of LWFDM are more accurate and numerical outcomes of table (8) elucidate that except for third-and fourth-members the results of LWFDM are more accurate. In conclusion, it can easily say that the numerical results of LWFDM for all cases are more accurate and reliable. Even in the cases that FOFDM obtained better results, the differences were negligible. One of the main points behind the better performance of LWFDM in all case studies has to do with boundary conditions. As is evident 
to all, boundary conditions have a significant impact on the accuracy of numerical methods. FOFDM needs to consider more ghost node points than LWFDM. This fact affects, first of all, the accuracy of numerical results, and secondly, it makes the process of developing a model cumbersome. The last but not least point is that in all case studies the required execution time for LWFDM was much shorter than the FOFDM.

Fig. 3.

Table 5. Parameter values for the third case

\begin{tabular}{|c|c|c|c|c|}
\hline Description & $\mathrm{C}_{1}(\mathrm{~m}=1)$ & $\mathrm{C}_{2}(\mathrm{~m}=2)$ & $\mathrm{C}_{3}(\mathrm{~m}=3)$ & $\mathrm{C}_{4}(\mathrm{~m}=4)$ \\
\hline Retardation coefficient $\left(R_{m}\right)$ & 5.3 & 1.9 & 1.2 & 1.3 \\
\hline Decay coefficient, $\lambda_{m} \times 10^{-4}\left(\right.$ day $\left.^{-1}\right)$ & 7 & 5 & 4.5 & 0 \\
\hline Third case $\rightarrow C(x, 1)(\mathrm{mM})$ & 0 & 0 & 0 & 0 \\
\hline Third case $\rightarrow C(1, t)(\mathrm{mM})$ & 100 & 0 & 0 & 0 \\
\hline Third case $\rightarrow C(N, t)(\mathrm{mM})$ & 0 & 0 & 0 & \\
\hline Pore velocity $=1$ mday $^{-1}$ & Dispersion coefficient & $\mathrm{D}=10 \mathrm{~m}^{2}$ day $^{-1}$ & \\
\hline
\end{tabular}

Table 6. Table of TMSE for the third case

\begin{tabular}{|c|c|c|c|c|c|c|}
\hline Description & $\mathrm{Nx}(\Delta \mathrm{x}) ; \mathrm{Nt}(\Delta \mathrm{t})$ & $\mathrm{C}_{1}(\mathrm{~m}=1)$ & $\mathrm{C}_{2}(\mathrm{~m}=2)$ & $\mathrm{C}_{3}(\mathrm{~m}=3)$ & $\mathrm{C}_{4}(\mathrm{~m}=4)$ & Execution time(s) \\
\hline Third case $\rightarrow$ LWFDM & \multirow[t]{2}{*}{$1001(3) ; 15001(0.2)$} & 0.00341617 & 0.006046303 & 0.001608776 & 0.001715191 & 7.508856 \\
\hline Third case $\rightarrow$ EFOFDM & & 0.004821301 & 0.008065866 & 0.001719605 & 0.001823453 & 26.554933 \\
\hline Third case $\rightarrow$ LWFDM & \multirow[t]{2}{*}{ 1501(2);30001(0.1) } & 0.003486966 & 0.006025762 & 0.001668566 & 0.00176801 & 21.480427 \\
\hline Third case $\rightarrow$ EFOFDM & & 0.00431609 & 0.00723868 & 0.001711212 & 0.001815357 & 88.527707 \\
\hline Third case $\rightarrow$ LWFDM & \multirow[t]{2}{*}{$2001(1.5) ; 40001(0.075)$} & 0.003565671 & 0.005966808 & 0.001686528 & 0.001782023 & 55.981296 \\
\hline Third case $\rightarrow$ EFOFDM & & 0.004144471 & 0.00682945 & 0.001717049 & 0.001818372 & 152.220120 \\
\hline Third case $\rightarrow$ LWFDM & \multirow[t]{2}{*}{ 2001(1.5);60001(0.05) } & 0.003561612 & 0.005933962 & 0.001706274 & 0.001796552 & 57.247254 \\
\hline Third case $\rightarrow$ EFOFDM & & 0.004145105 & 0.006812481 & 0.001713147 & 0.001812118 & 202.831910 \\
\hline
\end{tabular}


Table 7. Table of $\mathrm{L}_{2}$-norms for the third case

\begin{tabular}{|c|c|c|c|c|c|c|}
\hline $\mathrm{L}_{2^{-}}$ & Description & $\operatorname{Nx}(\Delta x) ; \operatorname{Nt}(\Delta t)$ & $\mathrm{C}_{1}(\mathrm{~m}=1)$ & $\mathrm{C}_{2}(\mathrm{~m}=2)$ & $\mathrm{C}_{3}(\mathrm{~m}=3)$ & $\mathrm{C}_{4}(\mathrm{~m}=4)$ \\
\hline \multirow{13}{*}{$\begin{array}{l}\text { Third } \\
\text { case }\end{array}$} & Analytical results of equal interval node distribution & \multirow[t]{3}{*}{$1001(3) ; 15001(0.2)$} & 677.3394 & 909.7015 & 566.1908 & 180.1968 \\
\hline & LWFDM & & 678.2099 & 909.6674 & 565.8571 & 179.7832 \\
\hline & EFOFDM & & 678.7518 & 909.7855 & 565.8606 & 179.7525 \\
\hline & Analytical results of equal interval node distribution & \multirow[t]{4}{*}{$1501(2) ; 30001(0.1)$} & & & & \\
\hline & & & 828.0354 & 1114.147 & 693.4388 & 220.6947 \\
\hline & LWFDM & & 829.0513 & 1114.154 & 693.005 & 220.1615 \\
\hline & EFOFDM & & 829.4979 & 1114.226 & 693.007 & 220.1427 \\
\hline & Analytical results of equal interval node distribution & \multirow[t]{3}{*}{ 2001(1.5);40001(0.075) } & 955.2477 & 1286.505 & 800.7144 & 254.8364 \\
\hline & LWFDM & & 956.4115 & 1286.528 & 799.0596 & 252.4782 \\
\hline & EFOFDM & & 956.7907 & 1286.589 & 799.0635 & 252.4662 \\
\hline & Analytical results of equal interval node distribution & \multirow[t]{3}{*}{ 2001(1.5);60001(0.05) } & 955.2477 & 1286.505 & 800.7144 & 254.8364 \\
\hline & LWFDM & & 956.3931 & 1286.538 & 799.0523 & 252.4712 \\
\hline & EFOFDM & & 956.7896 & 1286.58 & 799.0548 & 252.4627 \\
\hline
\end{tabular}

Table 8. Table of $\mathrm{L}_{\infty}$-norms for the third case

\begin{tabular}{|c|c|c|c|c|c|c|}
\hline $\mathrm{L}_{\infty^{-}}$ & Description & $\mathrm{Nx}(\Delta \mathrm{x}) ; \mathrm{Nt}(\Delta \mathrm{t})$ & $\mathrm{C}_{1}(\mathrm{~m}=1)$ & $\mathrm{C}_{2}(\mathrm{~m}=2)$ & $\mathrm{C}_{3}(\mathrm{~m}=3)$ & $\mathrm{C}_{4}(\mathrm{~m}=4)$ \\
\hline \multirow{12}{*}{ Third case } & Analytical results of equal interval node distribution & \multirow[t]{3}{*}{$1001(3) ; 15001(0.2)$} & 98.22275 & 60.78184 & 31.70163 & 10.485 \\
\hline & LWFDM & & 98.93161 & 60.77521835 & 31.67349 & 10.4398 \\
\hline & EFOFDM & & 99.01777 & 60.79262064 & 31.67862 & 10.44122 \\
\hline & Analytical results of equal interval node distribution & \multirow[t]{3}{*}{$1501(2) ; 30001(0.1)$} & 98.45076 & 60.78459 & 31.70348 & 10.485 \\
\hline & LWFDM & & 99.28634 & 60.78333125 & 31.67441 & 10.43943 \\
\hline & EFOFDM & & 99.34206 & 60.79199843 & 31.67697 & 10.44015 \\
\hline & Analytical results of equal interval node distribution & \multirow[t]{3}{*}{$2001(1.5) ; 40001(0.075)$} & 98.56202 & 60.78432 & 31.70441 & 10.485 \\
\hline & LWFDM & & 99.46425 & 60.78531858 & 31.67464 & 10.43935 \\
\hline & EFOFDM & & 99.50531 & 60.79180174 & 31.67656 & 10.43989 \\
\hline & Analytical results of equal interval node distribution & \multirow[t]{3}{*}{ 2001(1.5);60001(0.05) } & 98.56202 & 60.78432 & 31.70441 & 10.485 \\
\hline & LWFDM & & 99.46423 & 60.78724772 & 31.67486 & 10.43927 \\
\hline & EFOFDM & & 99.50531 & 60.79155971 & 31.67614 & 10.43962 \\
\hline
\end{tabular}




\section{Conclusion}

This paper documented the development of a new numerical model based on the two different schemes of FDM (i.e., LWFDM and FOFDM) that solved the multi-species solute transport phenomenon in porous media. Although there is no limitation on the number of multi-species, the analytical results of three different well-established problems (i.e., threespecies $\left(\mathrm{NH}_{4}^{+} \rightarrow \mathrm{NO}_{2}^{-} \rightarrow \mathrm{NO}_{3}^{-}\right)$and four-species problems) are applied to evaluate the proposed model. TMSE, $\mathrm{L}_{2^{-}}$and $\mathrm{L}_{\infty}$ norms have been employed to obtain an accurate analysis of the numerical results.

With regard to the numerical results given in this paper, both the LWFDM and FOFDM have calculated acceptable results. The numerical experiments for all of the case studies were carried out with at least two various numbers of space- and time intervals. In the first case study, the numerical outcomes express that the FOFDM in the first- $\left(\mathrm{NH}_{4}^{+}\right)$and secondmember $\left(\mathrm{NO}_{2}^{-}\right)$determined slightly better results than LWFDM. On the other hand, the LWFDM determined more accurate results for $\mathrm{L}_{2^{-}}$and $\mathrm{L}_{\infty}$-norms. In the last two cases, in general, the LWFDM are found more precise outcomes than FOFDM. As a final point, it can be stated that in all case studies the required execution time for LWFDM was much shorter than the FOFDM. In conclusion, it can easily be said that the LWFDM is a more accurate and reliable method than the FOFDM.

\section{Acknowledgements}

This research did not receive any specific grant from funding agencies in the public, commercial, or not-for-profit sectors.

\section{References}


Bagalkot, N., \& Kumar, G.S. 2015. Effect of nonlinear sorption on multispecies radionuclide transport in a coupled fracture-matrix system with variable fracture aperture: a numerical study, ISH Journal of Hydraulic Engineering, 21(3): 242-254.

Bauer, P., Attinger, S., \& Kinzelbach, W. 2001. Transport of a decay chain in homogenous porous media: analytical solutions, Journal of Contaminant Hydrology, 49: 217-239.

Celiker, M. 2016. Determination of the interaction between groundwater and surface water using environmental isotopes (Oxygen-18, Deuterium and Tritium) and chemical analyses in Uluova Region, Elazig, Turkey, Journal of Engg. Research, 4(1):105-124.

Chen-Charpentier, B.M., Dimitrov, D.T., \& Kojouharov, H.V. 2009. Numerical simulation of multi-species biofilms in porous media for different kinetics, Mathematics and Computers in Simulation, 79: 1846-1861.

Dalkiliç, H.Y., \& Gharehbaghi A. 2021. Numerical modeling of groundwater flow based on explicit and fully implicit schemes of finite volume method, Journal of Engg. Research, 9 (4B):56-69, DOI:10.36909/jer.9253.

Das, P., Akhter, A., \& Singh, M. K. 2018. Solute transport modelling with the variable temporally dependent boundary, Sadhana, 43(12):1-11.

Gharehbaghi, A. 2016. Explicit and implicit forms of differential quadrature method for advection-diffusion equation with variable coefficients in semi-infinite domain, journal of hydrology, 541: 935-940. http://dx.doi.org/10.1016/j.jhydrol.2016.08.002

Gharehbaghi, A. 2017. Third- and fifth-order finite volume schemes for advection-diffusion equation with variable coefficients in semi-infinite domain. Water and Environment Journal, 31(2): 184-193. doi:10.1111/wej.12233

Gharehbaghi, A., Kaya, B., \& Tayfur, G. 2017. Comparative Analysis of Numerical Solutions of Advection-Diffusion Equation, Cumhuriyet University Science Journal (CSJ), 38(1):73-84. http://dx.doi.org/10.17776/csj.53808 
Kaya, B., \& Arisoy, Y. 2011. Differential Quadrature Solution for One-Dimensional Aquifer Flow, Mathematical and Computational Applications, 16(2): 524-534.

Kaya, B., \& Gharehbaghi, A. 2014. Implicit Solutions of Advection Diffusion Equation by Various Numerical Methods. Aust. J. Basic \& Appl. Sci., 8(1), 381-391

Kumar, A., Kumar, D., \& Kumar, J.N. 2010. Analytical solutions to one-dimensional advection-diffusion equation with variable coefficients in semi-infinite media. J. Hydrol. 380: 330-337.

Natarajan, N., \& Kumar, S.G. 2010. Finite difference approach for modeling multispecies transport in porous media, International Journal of Engineering Science and Technology, 2(8): 3344-3350.

Pathania, T., Eldho, T.I., \& Bottacin-Busolin, A. 2020. Coupled simulation of groundwater flow and multispecies reactive transport in an unconfined aquifer using the element-free Galerkin method, Engineering Analysis with Boundary Elements, 121: 31-49.

Pérez Guerrero, J.S., Skaggs, T.H., \& van Genuchten, M.T. 2009. Analytical Solution for Multi-Species Contaminant Transport Subject to Sequential First-Order Decay Reactions in Finite Media, Transp. Porous Med, 80:373-387. DOI 10.1007/s11242-009-9368-3

Ramos, T.B., Simunek, J., Gonçalves, M.C., Martins, J.C., Prazeres, A., Castanheira, N.L., \& Pereira, L.S. 2011. Field evaluation of a multicomponent solute transport model in soils irrigated with saline waters, Journal of Hydrology, 407(1-4): 129-144.

Savovic, S., \& Djordjevich, A. 2012. Finite difference solution of the one-dimensional advection-diffusion equation with variable coefficients in semi-infinite media. Int. J. Heat Mass Transf. 55: 4291-4294. http://dx.doi.org/10.1016/j. ijheatmasstransfer.2012.03.073

Savovic, S., \& Djordjevich, A. 2013. Numerical solution for temporally and spatially dependent solute dispersion of pulse type input concentration in semi-infinite media. Int. J. Heat Mass Transf. 60, 291-295. http://dx.doi.org/10.1016/j.ijheatmasstransfer.2013.01.027 
Savovic, S., Djordjevich, A., Tse, P.W., \& Nikezic, D., 2011. Explicit finite difference solution of the diffusion equation describing the flow of radon through soil, Applied Radiation and Isotopes, 69: 237-240. doi:10.1016/j.apradiso.2010.09.007

Sharma, A., Guleria, A., \& Swami, D. 2016. Numerical modelling of multispecies solute transport in porous media, Hydro 2016 international conference, 159-169.

Singh, M.K., Ahamad, S., \& Singh, V. P. 2012. Analytical Solution for One-Dimensional Solute Dispersion with Time-Dependent Source Concentration along Uniform Groundwater Flow in a Homogeneous Porous Formation, Journal of Engineering Mechanics,138(8).10451056

Torlapati, J. 2013. Development and Application of One Dimensional Multi-Component Reactive Transport Models, Phd. dissertation, Alabama

Zhang, Z.h., Zhang, J.P., Ju, Z.Y., \& Zhu, M. 2018. A one-dimensional transport model for multi-component solute in saturated soil, Water Science and Engineering, 11(3): 236-242.

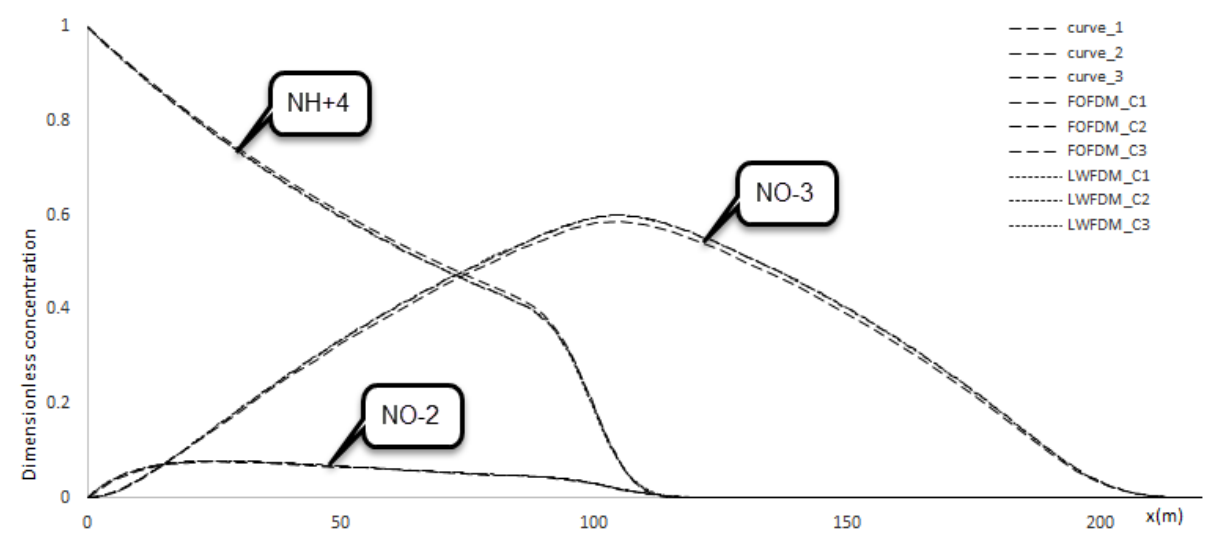

Fig. 1. Illustration of results of first case for $1 D$ transient concentration distribution for all the nitrogen species $(220 \mathrm{~cm}$ and 200h) and $\left(\mathrm{N}_{\mathrm{x}}=331, \mathrm{~N}_{\mathrm{t}}=800001\right)$. 


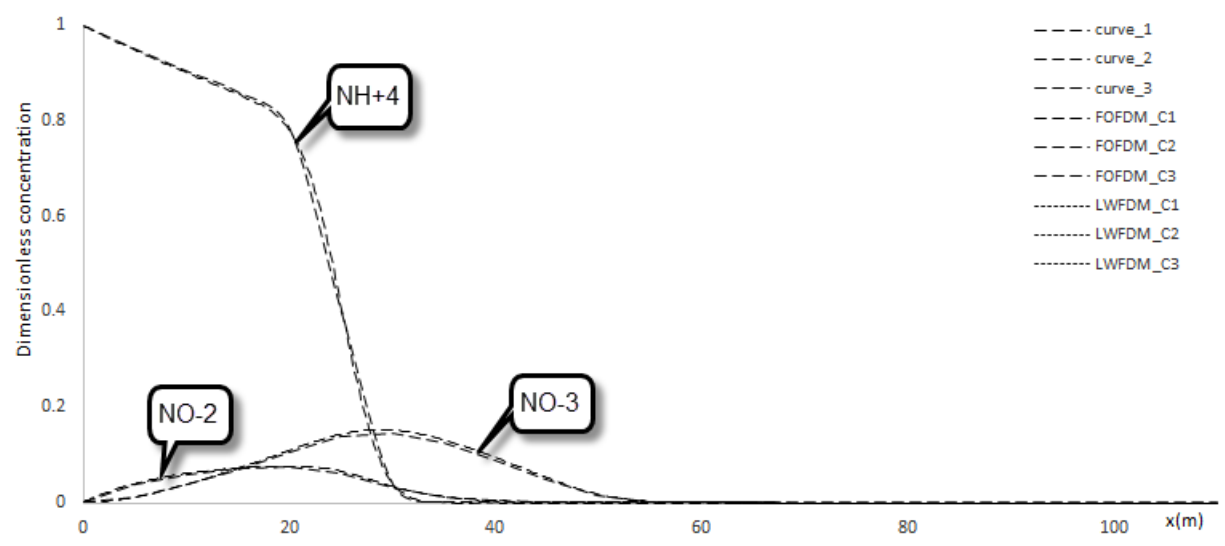

Fig. 2. Illustration of results of second case for 1D transient concentration distribution for all the nitrogen species $(110 \mathrm{~cm}$ and 50h) and $\left(\mathrm{N}_{\mathrm{x}}=441, \mathrm{~N}_{\mathrm{t}}=60001\right)$.

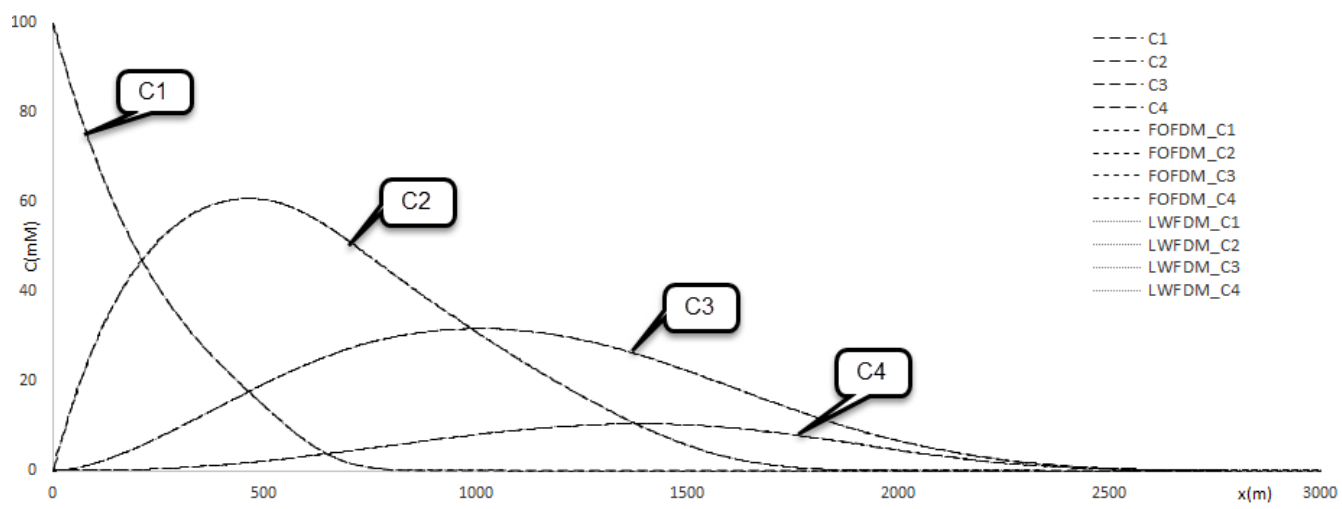

Fig. 3. 1D transient concentration distribution for constant boundary condition ( $3000 \mathrm{~m}$ and 3000 day) in $\left(\mathrm{N}_{\mathrm{x}}=1001\right.$, $\left.\mathrm{N}_{\mathrm{t}}=15001\right)$. 